\title{
SUPPORTING STUDENT TRANSITIONS: INTEGRATING LIFE DESIGN, CAREER CONSTRUCTION, HAPPENSTANCE, AND HOPE
}

\section{J. J. Peila-Shuster}

School of Education

Counseling and Career Development

Colorado State University

Fort Collins, CO United States of America

e-mail: Jackie.Peila-Shuster@colostate.edu

\section{Abstract}

This article provides an integrated theoretical approach to conceptualize and support transitions of students in higher education towards their professional lives. The life design paradigm serves as a foundational anchor to the integration of career construction theory, happenstance learning theory, and hope theory. These theories are then applied to the 4S transition model to provide potential avenues for career counselors to follow in their work with students. It is imperative for career counselors to partner with students in higher education in learning how to successfully navigate transitions as they will face a multitude of them throughout their lives.

Keywords: life design, career construction, happenstance, happenstance learning theory, hope, transitions, career adaptability, 4S transition model

\section{INTRODUCTION}

Young adults have certain similar developmental tasks, such as successfully gaining and consolidating a sense of their own identity (Erikson 1950), and exploring themselves and career options while moving towards the establishment of themselves in their first professional job (Super 1980). This time of emerging adulthood has been characterized as highly stressful which can be partially attributed to high levels of instability and uncertainty (Kuwabara, Van Voorhees, Gollan and Alexander 2007). This is especially salient for college students as they move into and through numerous transitions from their secondary education to (and through) higher education, and onto their transition to the world of work.

Successfully managing and facilitating transitions is particularly important when considering today's world of work and the vast changes that have occurred in a relatively short time. Individuals are no longer able to look to their employing organizations to help define their career paths, nor can they expect to be with one organization for a large part of their career. In the United States in 2014, 49.2 per cent of workers ages 20-24 had been with their current employer for 12 months or less (Bureau of Labor Statistics 2014). Furthermore, the evolving 
world of work will require enhancing skill sets and areas of expertise. According to Hrabowski (2015), those entering the workforce will need a deep knowledge of their area of work; have agility with technology; be able to engage with interdisciplinary and cross-functional teams to critically think about and solve problems; and possess high quality communication skills, flexibility, and emotional intelligence.

Additionally, Schwab (2016) described a 'Fourth Industrial Revolution' that our global society is currently experiencing. This industrial revolution is building on the digital revolution that has been in process since the middle of the last century. However, this fourth revolution 'is characterized by a fusion of technologies that is blurring the lines between the physical, digital, and biological spheres' (Schwab 2016, para 2). He argues that this revolution is not simply a prolongation of the digital revolution because the speed, scope, and impact of current breakthroughs are exponential rather than linear, and historically unprecedented. Thus, the Fourth Industrial Revolution

will change not only what we do but also who we are. It will affect our identity and all the issues associated with it: our sense of privacy, our notions of ownership, our consumption patterns, the time we devote to work and leisure, and how we develop our careers, cultivate our skills, meet people, and nurture relationships. (Schwab 2016, para. 26).

Consequently, not only are students in higher education transitioning to a vastly changing world of work, they are also entering an extraordinarily changing global world which will impact them personally as well as professionally.

This article provides an integrated theoretical approach to facilitate transitions of students in higher education towards their professional lives. By pulling from the life design paradigm (Guichard 2015; Savickas 2012), career construction theory (Savickas 2013), happenstance learning theory (Krumboltz 2009), and hope theory (Snyder 2002), career counselors can partner with students in higher education to engage in successful transitions within higher education and onto their professional lives.

\section{SCHLOSSBERG'S TRANSITION FRAMEWORK}

In helping students with transitions, it is useful to have a framework to conceptualize the transition and what is needed to move through it. Schlossberg, Waters and Goodman $(1995,27)$ defined transition as 'any event, or nonevent, that results in changed relationships, routines, assumptions, and roles'. Nancy Schlossberg's (1994) transition framework can be useful in considering transition identification, the transition process, one's resources for dealing with the transition, and how one can strengthen those resources for navigating the transition. Her 
framework provides a structural approach that concurrently honors the variability of each individual (Anderson, Goodman and Schlossberg 2012).

According to Anderson et al. (2012), transitions are comprised of: 1) approaching the transition, 2) taking stock of coping resources, and 3) taking charge by strengthening one's resources. Approaching the transition involves identifying the transition and where one is in the transition process. A transition can be identified according to the nature of it (anticipated, unanticipated, a chronic hassle, or a non-event) and its significance or impact on the individual's life. Furthermore, it must be recognized by the individual as a transition, otherwise it is just a 'change' with little significance attached to it. Locating where one is in the transition involves gaining a sense of whether the individual is moving into the transition, moving through it, or moving out of it.

The 4S system developed by Schlossberg comprises the taking stock segment of the transition framework and helps identify potential resources one can call upon to successfully cope with the transition (Anderson et al. 2012). The four S's are as follows (Anderson et al. 2012; Schlossberg 1994):

1) Situation consists of the characteristics of the transition. For example, what kind of transition is it, how is it perceived, where is the individual in the process of it, are there other stressors or transitions occurring simultaneously?

2) Self is comprised of the individual's personal characteristics, psychological resources, and demographic variables. For example, what are the individual's strengths/ weaknesses, what barriers or oppression does she/he face, what is her/his previous experience with similar transitions, does she/he believe there are options, is she/he able to deal with ambiguity?

3) Supports involve the types of help that are available. For example, what people will help or hinder, in what ways do they give (or not give) support, are there other options for support?

4) Strategies involve the individual's style of coping. Does the individual use more than just one coping strategy; can she/he change the situation, the meaning of the situation, or manage their reactions to the stress?

After taking stock of the transition, the career counselor can partner with the individual to 'take charge' of it by identifying coping strategies that are working, as well as developing new ones and determining action plans (Anderson et al. 2012). While multiple aspects of transitions may 
be beyond one's control, by taking charge of strengthening one's resources, individuals can gain some sense of control and move forward, while also acknowledging that which is outside of their control.

\section{LIQUID MODERNITY AND LIFE DESIGN}

According to Bauman, individuals now live in liquid modernity in which the social structures and institutions that limit individual choices and shape routines or patterns of acceptable behavior dissolve too quickly to serve as solid reference points (as cited in Guichard 2015). These liquid societies do not provide students in today's world with the sturdy social, organizational, and ideological frameworks that guided their parents in terms of what is a 'normal' way of life, what roles men and women should fulfill, and what makes life meaningful (Guichard 2015). Instead, individuals live their life trajectories with indistinct and/or elusive maps, and thus must find their own ways in this world. By taking into account individuals' life stories that are an extension of their unique cultures and contexts, and are embedded within their historical place in time, career counselors can better serve all individuals, including students in higher education.

With this new paradigm of liquid modernity, there are three key types of career interventions that can be useful. Rather than just categorizing all interventions together as 'career advising' or 'career coaching' or 'career counseling', career specialists would do well to be informed of the differences between career interventions. Guichard $(2015,18)$ discusses career guidance and advising interventions as those that 'help individuals build a vocational self-concept appropriate to the current world of work'. These interventions can be divided into those that are based on two different paradigms, guidance and education (Guichard 2015; Savickas 2012). Savickas (2012) indicated that the paradigm for career guidance focuses on enhancing self-knowledge, increasing occupational information, and matching those two (Savickas 2012), thus helping clients develop a vocational self-concept that is congruent with common employability norms (Guichard 2015). Career education, according to Savickas (2008, 2012), has an emphasis on learning the process of developing one's career and attempts to assess one's development status, orient the individual to upcoming career development tasks, and help her/him cultivate the attitudes and competencies needed to successfully accomplish those tasks. Career education includes learning about job activities and requirements, educational requirements, employment prospects, and recruiting procedures such as résumés, cover letters, and job applications (Guichard 2015).

Taken together, the interventions involving career guidance, advising, and education have 
often been the major activities involved in higher education career centers. Career specialists in higher education help individuals gain self-knowledge, knowledge about the world of work, how one 'fits' into that world of work, and how one gains entry to that world through various means, including job search skills and connections to networking, internship, and employment opportunities. However, there is so much more to life transitions than this, and that is where career counseling and life design share a special niche by allowing for the 'individual', and all that goes on with that unique life, to be brought back into the puzzle. Individual life trajectories in today's world of liquid modernity call for 'a science of intervention that deals with constructing a self and designing a career' (Savickas 2012,14) and are not conducive to a onesize-fits-all approach.

Students in higher education face transitions that do not have the same scripts and maps as in previous times. They head into a world in which career trajectories are no longer stable, occupational prospects are more fluidly defined and less predictable, and job transitions are more frequent (Savickas et al. 2009). They must know how to be ‘Knowledge Nomads’ to cope with this new world of work by embracing flexibility and technology, and creating new opportunities that provide value (Feller and Whichard 2005). They must learn to take control of and define their own career trajectories, engage in lifelong learning, and achieve a level of adaptability that allows them to construct their careers in flat organizations and a global society. Workers must learn to navigate uncertain and insecure employment through flexibility, lifelong learning, and adapting to occupational transitions; they must prepare for possibilities rather than make plans (Savickas 2013).

'Entering today's work world requires more effort, deeper self-knowledge, and greater confidence than ever before' (Savickas 2012, 13). Thus, a sense of identity is critical, and can offer the consistency that helps individuals make meaning of their past to carry them forward to their futures. Finding consistency, coherence, and continuity of one's identity, and within their life stories can help individuals cope with the instability and uncertainties that come with today’s changing workplace and lack of structured career paths (Savickas 2012).

As workers move from one assignment to the next assignment, they must let go of what they did yet not who they are. If they let go of everything, then the loss may overwhelm them. By holding onto the self in the form of a life story that provides coherence and continuity, they are able to pursue their purpose and projects with integrity and vitality. (Savickas 2012, 14).

It is important to understand that 'self' and identity are not one in the same. Identity is how individuals think of themselves in relation to their social roles; it is the reconciliation of when the self comes up against the social world with resultant identity formation (Savickas 2012). 
Thus, as higher education students transition from their education to the work world, they must work to gain a renewed sense of identity as a 'worker' and as a professional within the work context they will be entering.

Within the life design paradigm, the idea of self-actualization is replaced with selfconstruction and steers away from career decidedness as the ultimate goal (Savickas 2012). To do this, career counselors engage in 'life design dialogues' (Guichard 2015, 18) that assist individuals in developing the reflexivity that is required to design their lives in ways that help them consider and define their own norms without depending upon the social norms of employability as is done in career guidance. According to Savickas (2012), the career counselor using an intervention within the life design paradigm uses small stories with the client to construct career stories, and then deconstructs the stories to critically evaluate them in a conscious manner. This deconstruction can illuminate assumptions, omissions, and what was overlooked or inadequately addressed. Next, the client and counselor reconstruct the stories in a grander narrative that defines (or redefines) one’s identity narrative or 'life portrait' (Savickas 2012, 15). This narrative, according to Savickas (2012), helps give the person a sense of personal meaning and social mattering in their life and from that point, the counselor and client can more clearly coconstruct intentions that will facilitate movement into the individual's next life chapter.

\section{CAREER CONSTRUCTION THEORY}

Situated within the life design paradigm, Savickas' (2005; 2013) career construction theory asserts that careers do not just unfold, but instead are co-constructed by individuals through interpersonal processes as they make career choices that can help express their self-concepts and substantiate their goals. While an individual has an objective career and career path as seen by others, she/he must also construct a subjective career that imposes meaning on, guides, and sustains vocational behavior across transitions (Savickas 2005; 2013). In using career construction counseling, clients tell stories about their work lives as well as current transitions and issues and then integrate those stories into 'an identity narrative about self and work' (Savickas 2013, 168). This narrative about self and work is used to make meaning of the transition one is undergoing and to regulate emotions, and ultimately helps to determine what is next and prompts action towards a more satisfying life (Savickas 2013). For a more in depth understanding of career construction theory and career construction counseling, the reader is referred to Savickas (2013; 2015).

The two metacompetencies highlighted in career construction theory are: 1) identity, 
which, as just described, gives personal meaning to vocational behavior and work activities within individuals’ lives, and 2) career adaptability. According to Savickas and Porfeli (2012, 662), career adaptability represents individuals' 'resources for coping with current and anticipated tasks, transitions, traumas in their occupational roles that ... alter their social integration'. The four dimensions of career adaptability are: 1) career concern - developing a future orientation towards work and feeling optimistic about it; 2) career control - developing self-regulation to engage in vocational tasks and transition processes; 3) career curiosity - being inquisitive about work, open to new experiences and experimenting with future possibilities; and 4) career confidence - acquiring and enhancing self-efficacy to pursue aspirations and execute a plan of action to make and implement educational and career choices (Hartung, Porfeli and Vondracek 2008; Savickas 2013; Savickas and Porfeli 2012).

These four dimensions of career adaptability come together 'to regulate the continuous dynamic, multifactorial, mutidirectional, and nonlinear interactions between people and their environment, allowing them to adjust to their contextual and social environment' (Rossier 2015, 155). This ability to adjust is extremely critical during times of transition because, according to Rossier (2015), it can help individuals cope with uncertainty and manage ambiguity. Additionally, career adaptability has been found to be positively related to vocational identity (Porfeli and Savickas 2012), vocational development (Rocha 2012), a broader range of interests and fewer perceived internal and external barriers for adolescents (Soresi, Nota and Ferrari 2012), and self-esteem (van Vianen, Klehe, Koen and Dries 2012).

\section{HAPPENSTANCE LEARNING THEORY}

Another theory that career counselors can integrate with career construction theory to facilitate students' successful transitions within higher education and to the work world is happenstance learning theory (HLT) (Krumboltz 2009). This theory has evolved from Krumboltz's (1996) learning theory of career counseling. Still embedded within HLT are the proposals regarding why people behave the way they do, which are derived from genetic influences, instrumental and associative learning experiences, and environmental conditions and events (Krumboltz 2009).

The first fundamental proposition of HLT is that the goal of career counseling is to help clients learn to take actions to achieve more satisfying career and personal lives, not to make a single career decision (Krumboltz 2009). Thus, career counselors play a key role in helping students learn career development processes and ways to take action; and these actions are not undertaken just to make a single career decision, but are instead to help them achieve 
satisfaction in their personal as well as career lives. The importance of the first proposition cannot be understated given the uncertainty of life and career trajectories in today's liquid modernity and the unlikely ability to predict one satisfying lifetime occupation. Furthermore, it speaks to the complexity of the work career counselors do because it highlights the interplay of personal and career counseling in designing a life and taking the necessary actions to do so. According to Krumboltz (2009, 142), 'career counselors should be able to help people handle many transitions in Life, not just the transition from school to work'.

Secondly, HLT proposes that career assessment is to be used to stimulate learning, not to match people to occupations (Krumboltz 2009). Career assessments such as interest inventories are effective and efficient methods that tell the story of how the person is similar to socially constructed clusters of interests, attitudes, and skills (Savickas 2013). They do not get to personal meaning and mattering for the unique individual, nor do they foretell the future since individuals may gain new interests depending on the contexts and opportunities afforded to them. Other career assessments can provide points of exploration about what one values in work and life, one's self-efficacy in being successful with various activities, and what assumptions and beliefs may be contributing to career and/or life difficulties, to name just a few examples.

The third proposition of HLT is that clients can help generate beneficial unplanned events by learning to engage in exploratory actions (Krumboltz 2009). This draws upon the competency of career curiosity within the meta-competency of career adaptability as defined by Savickas and Porfeli (2012) and discussed previously. Happenstance is not passive in this theory, but instead something that is achieved through actions and thoughtful reflection. Unplanned events are a constant in life. Rather than letting these events pass by, career counselors can help students learn to position themselves to experience unplanned events and sensitize them to recognize the potential opportunities these events present. The more conscious one becomes of unplanned events, the more one can be attentive to potential opportunities. Then, through conscientious deliberation, one can choose which opportunities to take action on, as well as when and how to do so, thus building the competency of career control.

Finally, the fourth proposition of HLT states that success of career counseling is not based on what happens within the counseling session, but is instead assessed by what clients do in their world outside of counseling (Krumboltz 2009). The important learning, according to Krumboltz (2009), occurs within the client's real world, so it is imperative to engage with students in planning actions and activities to participate in after they leave the counselor's office. Through these actions and activities, students can further develop the competencies of career control and confidence as they build upon successes. 


\section{HOPE THEORY}

Hope is 'the perceived capability to derive pathways to desired goals, and motivate oneself via agency thinking to use those pathways' (Snyder 2002, 249). Thus, there are three primary components to hope: goal directed thought, pathways thinking, and agency thought. One’s goals may vary in terms of temporal frames (e.g., short term versus long term) and specificity, with vague goals being less likely to occur in highly hopeful thinking (Snyder 2002). This is an important consideration since some higher education students have vague career goals that lead to an absence of strategies for how to fulfill their career aspirations (Nachmias and Walmsley 2015). Additionally, individuals that have high hope typically prefer stretch goals, which are goals that are slightly more difficult to attain than previously set and achieved goals (Lopez et al. 2004).

The second component to hope, pathways thinking, involves the routes and strategies to meet goals and are how individuals link their present selves with imagined futures (Snyder 2002). According to Snyder (2002), those with high levels of hope are able to generate plausible routes to goals, whereas those with low hope tend to develop more tenuous goal pathways and few to no alternatives.

Lastly, the third element of hope is agency thought, or the mental energy (and motivation) directed towards reaching goals (Snyder 2002). This mental energy is necessary for goal achievement because one must have the mental energy that is required to initiate and continue to use pathways to pursue goals, especially in the face of obstacles and the need to employ alternative strategies.

These elements of hope are intertwined and additive to each other (Lopez et al. 2004; Snyder 2002). For example, while good motivation is necessary to reach goals, if there are few strategies for goal achievement, then the goals are less likely to be realized. Likewise, even with good strategies, perseverance in the face of obstacles is unlikely without motivation to reach goals. Furthermore, high levels of pathways and agentic thinking can create an upward spiral that fuels more fluid pathways and agency thoughts throughout goal pursuit (Snyder 2002).

As higher education students transition from their academic to professional lives, it is imperative to generate strategies with them that can help them build and maintain the critical psychological resource of hope. Hope supports and sustains individuals through transitions and can be built when career counselors partner with students to create desirable and achievable stretch goals, to produce a variety of pathways to these goals, and to help them to identify motivations and resources that will sustain their mental energy and agency to persevere in the 
face of obstacles. Hope is also an important ingredient in career adaptability as it can facilitate optimism about the future (career concern) and an openness to new experiences (career curiosity). It can also sustain students as they develop the behaviors and self-regulation necessary to engage in vocational tasks and transition processes (career control). Furthermore, as students put themselves in positions to generate beneficial unplanned events and execute action plans, they can build on successes to develop self-efficacy (career confidence).

Hope is also a part of life design counseling, not only contributing to the life design process, but also emerging from it. Maree (2015) found that life design counseling not only facilitated change in individuals' lives, but also encouraged action and infused hope. Additionally, it has been found that hope is correlated to all four dimensions of career adaptability, and that career curiosity and confidence mediated the relationship between hope and subcomponents of student satisfaction domains for high school students in Italy (Wilkins, Santilli, Ferrari, Nota and Soresi 2014). Hope also fits well with HLT since 'having a sense of hope allows a person to consider the possibilities in any situation and propels the individual to take action' (Niles 2011, 174).

\section{INTEGRATING AND APPLYING THEORY TO NAVIGATE TRANSITIONS}

The integration of career construction, happenstance learning, and hope theories, with an eye towards life design, can be applied to Schlossberg's transition framework leading to powerful directions for facilitating successful transitions. Each theoretical approach can support selfconstruction as individuals identify meaning and mattering in their lives, open themselves up to new opportunities, and build hope to carry them into their next life chapters.

In taking stock of the situation, as proposed by the 4S model (Schlossberg et al. 1995), it can be useful to help students situate themselves within their transitions in a manner that allows them to hold onto themselves and their sense of meaning and mattering. Using personal stories, deconstructing them to uncover assumptions and important messages, and reconstructing them into identity narratives allows individuals to gain a sense of personal meaning, make meaning of transitions, and consequently, identify future possibilities with a sense of coherence (Savickas 2012, 2013). Furthermore, using HLT helps students reframe indecision to openmindedness (Mitchell, Levin and Krumboltz 1999) and can nurture career curiosity and build hope.

When considering career construction, HLT, and hope theories in terms of the self in Schlossberg's model, identity, career adaptability, openness to unplanned events, and hope can be significant factors. In using career construction for self-authorship of one's life-career, 
identity narratives not only facilitate one's knowing of personal meaning and social mattering, but they can also propel one forward and prompt action (Savickas 2012, 2013). The career counselor and student can also identify which components of career adaptability need strengthening since career concern, control, curiosity, and confidence are all psychological resources necessary for successfully navigating career transitions. Furthermore, consideration of how unplanned events in the student's life have provided beneficial opportunities may open up the student to new opportunities. Assessing students' levels of hope and determining what components of hope are in need of strengthening also helps take stock of students' psychological resources and can provide areas on which to work.

In terms of supports, the career counselor and student can not only take stock of her/his support systems, but they can also use HLT to identify and create possibilities and networks. Additionally, hope theory can provide guidance in determining which supports can be used for encouragement and with whom the student can talk about pathways and goals. Finally, they can discuss which support resources students trust to share their newly co-constructed stories with, thus providing the opportunity for feedback to gain more clarity and coherence in their identity narratives.

In addition to identifying and evaluating strategies that individuals typically use for coping with and navigating through transitions, the career counselor and student can identify and develop new strategies that may be useful in the transition process. The grander narrative and career themes developed through career construction and life design dialogues can serve as a map, and an anchor, to these strategies. With career themes in mind, and a sense of personal meaning and social mattering through their identity, HLT can help direct action plans that encourage students to develop curiosity and put themselves in positions to benefit from unplanned events. Furthermore, a deepened sense of identity can assist them in assessing what opportunities they do or do not want to pursue, thus contributing to development of goals and alternative pathways, which are necessary components of hope. As hope is elevated, it 'becomes a catalyst for identifying ... goal-related action steps' (Niles 2011, 174), thus causing an upward spiral. Furthermore, the career counselor can help the individual build agency, another element of hope (Snyder 2002), by listening for action verbs in students's stories. According to Savickas $(2013,155)$ 'agency deals with the processes of resuming movement' and thus is typically 'revealed and discussed in the language of action verbs'.

While there are numerous mechanisms of human agency, and the action verbs of individuals' stories can help uncover agency, according to Bandura (2005), nothing is as essential to agency as one’s self-efficacy beliefs. Self-efficacy concerns one’s judgment about 
whether she/he is capable of producing a desired effect or accomplishing a certain level of performance (Bandura 1986). Self-efficacy beliefs affect people’s goals and aspirations, motivation levels, and levels of perseverance in the face adversity (Bandura 2006). They also help shape individuals' outcome expectations, which are judgments of how likely their efforts will produce favorable or undesirable outcomes.

According to Bandura $(1977,1986)$, performance accomplishments are the most powerful sources of efficacy information because they are based on the individual's own experiences of mastery. Successes build efficacy and failures reduce it. However, after strong efficacy expectations are developed, occasional failures are likely to have a diminished negative impact (Bandura 1977). Consequently, career counselors would do well to co-develop action plans with students that help them practice in the real world and build small successes into larger ones. Additionally, by reflecting upon previous successful experiences with similar transitions, career counselors can use HLT strategies to 'empower clients to see that their past successes contain lessons for present actions’ (Krumboltz 2009, 147).

As discussed in this article, the integration of these theories and their application to a transition model hold useful guidelines for career counselors working with students in transition. While the author has attempted to provide multiple connections of ideas, it should be emphasized that these are only starting points. A career counselor's creativity and thoughtfulness can undoubtedly add a multitude of directions worth pursuing.

\section{CONCLUSION}

An integrated theoretical approach to facilitate student transitions in higher education and towards their future careers can afford career counselors multiple strategies. With life design (Guichard 2015; Savickas 2012) as a guiding paradigm, Savickas' (2013) career construction theory, Krumboltz’s (2009) happenstance learning theory, and Snyder’s (2002) hope theory can all be useful within the framework of Schlossberg's (1994) transition model. Furthermore, career counselors must work to help students learn the process of navigating transitions as they will face a multitude of them throughout their lives. To do this, career professionals must avoid treating career development as an event consisting of a single decision point. Career, like life, is an ongoing journey consisting of multiple twists, turns, and decision points. Hence, it is imperative to assist individuals in learning career and life design processes, and partner with them to find their own hope, power, and resources that can help them journey forward throughout their many life chapters, celebrating successes and overcoming barriers. 


\section{REFERENCES}

Anderson, M. L., J. Goodman and N. K. Schlossberg. 2012. Counseling adults in transition: Linking Schlossberg's theory with practice in a diverse world. 4th ed. New York, NY: Springer.

Bandura, A. 1977. Self-efficacy: Toward a unifying theory of behavioral change. Psychological Review 84(2): 191-215.

Bandura, A. 1986. Social foundations of thought and action: A social cognitive theory. Englewood Cliffs, NJ: Prentice Hall.

Bandura, A. 2006. Toward a psychology of human agency. Perspectives on psychological science 1(2): 164-180.

Bureau of Labor Statistics. 2014. Employee Tenure in 2014. Washington, D.C.: U.S. Department of Labor. http://www.bls.gov/news.release/pdf/tenure.pdf

Erikson, E. H. 1950. Childhood and society. New York, NY: Norton.

Feller, R. and J. Whichard. 2005. Knowledge nomads and the nervously employed: Workplace change and courageous career choices. Austin, TX: PRO-ED.

Guichard, J. 2015. From vocational guidance and career counseling to life design dialogues. In Handbook of life design: From practice to theory and from theory to practice, ed. L. Nota and J. Rossier, 11-25. Boston, MA: Hogrefe.

Hartung, P. J., E. J. Porfeli and F. W. Vondracek. 2008. Career adaptability in childhood. The Career Development Quarterly 57(1): 63-74.

Hrabowski, F. A. 2015. The future of work: Preparing students for a changing world of work. Pacific Standard. http://www.psmag.com/business-economics/the-future-of-work-preparing-studentsfor-a-changing-world-of-work

Krumboltz, J. D. 1996. A learning theory of career counseling. In Handbook of career counseling theory and practice, ed. M. L. Savickas and W. B. Walsh, 55-80. Palo Alto, CA: Consulting Psychologists Press.

Krumboltz, J. D. 2009. The happenstance learning theory. Journal of Career Assessment 17(2): 135154. doi:10.1177/1069072708328861.

Kuwabara, S. A., B. W. Van Voorhees, J. K. Gollan and G. C. Alexander. 2007. A qualitative exploration of depression in emerging adulthood: Disorder, development, and social context. General Hospital Psychiatry 29(4): 317-324. doi:10.1016/j.genhosppsych.2007.04.001.

Lopez, S. J., C. R. Snyder, J. L. Magyar-Moe, L. M. Edwards, J. T. Pedrotti, K. Janowski and C. Pressgrove. 2004. Strategies for accentuating hope. In Positive psychology in practice, ed. P. A. Linley and S. Joseph, 388-404. Hoboken, NJ: John Wiley and Sons.

Maree, J. G. 2015. Research on life design in (South) Africa: A qualitative analysis. South African Journal of Psychology 45(3): 332-348.

Mitchell, K. E., A. S. Levin and J. D. Krumboltz. 1999. Planned happenstance: Constructing unexpected career opportunities. Journal of Counseling and Development 77(2): 115-124.

Nachmias, S. and A. Walmsley. 2015. Making career decisions in a changing graduate labour market: A hospitality perspective. Journal of Hospitality, Leisure, Sport and Tourism Education 17: 5058.

Niles, S. G. 2011. Career flow: A hope-centered model of career development. Journal of Employment Counseling 48(4): 173-175.

Porfeli, E. and M. L. Savickas. 2012. Career Adapt-Abilities Scale-USA form: Psychometric properties and relation to vocational identity. Journal of Vocational Behavior 80(3): 748-753.

Rocha, M. 2012. Transferable skills representations in a Portuguese college sample: Gender, age, adaptability and vocational development. European Journal of Psychology of Education 27(1): 77-90.

Rossier, J. 2015. Career adaptability and life design. In Handbook of life design: From practice to theory 
and from theory to practice, ed. L. Nota and J. Rossier, 153-167. Boston, MA: Hogrefe.

Savickas, M. L. 2005. The theory and practice of career construction. In Career development and counseling: Putting theory and research to work, ed. S. D. Brown and R. W. Lent, 42-70. Hoboken, NJ: John Wiley and Sons.

Savickas, M. L. 2008. Helping people choose jobs: A history of the guidance profession. In International handbook of career guidance, ed. J. A. Athanasou and R. van Esbroeck, 97-113. Dordrecht: Springer Netherlands.

Savickas, M. L. 2012. Life design: A paradigm for career intervention in the 21st century. Journal of Counseling and Development 90(1): 13-19. doi:10.1111/j.1556-6676.2012.00002.x.

Savickas, M. L. 2013. Career construction theory and practice. In Career development and counseling: Putting theory and research to work, ed. S. D. Brown and R. W. Lent, 147-183. 2nd ed. Hoboken, NJ: John Wiley and Sons.

Savickas, M. L. 2015. Life-design counseling manual. Publisher: Author.

Savickas, M. L., L. Nota, J. Rossier, J.-P. Dauwalder, M. E. Duarte, J. Guichard and A. E. M. van Vianen. 2009. Life designing: A paradigm for career construction in the 21st century. Journal of Vocational Behavior 75(3): 239-250. doi:10.1016/j.jvb.2009.04.004.

Savickas, M. L. and E. J. Porfeli. 2012. Career Adapt-Abilities Scale: Construction, reliability, and measurement equivalence across 13 countries. Journal of Vocational Behavior 80(3): 661-673. doi:10.1016/j.jvb.2012.01.011.

Schlossberg, N. K. 1994. Transition coping guidelines. Minneapolis, MN: Personal Decisions International.

Schlossberg, N. K., E. B. Waters and J. Goodman. 1995. Counseling adults in transition: Linking practice with theory. 2nd ed. New York, NY: Springer.

Schwab, K. 2016. The fourth industrial revolution: What it means, how to respond. World Economic Forum website: http://www.weforum.org/agenda/2016/01/the-fourth-industrial-revolution-whatit-means-and-how-to-respond

Snyder, C. R. 2002. Hope theory: Rainbows in the mind. Psychological inquiry 13(4): 249-275.

Soresi, S., L. Nota and L. Ferrari. 2012. Career Adapt-Abilities Scale-Italian form: Psychometric properties and relationships to breadth of interests, quality of life, and perceived barriers. Journal of Vocational Behavior 80(3): 705-711.

Super, D. E. 1980. A life-span, life-space approach to career development. Journal of Vocational Behavior 16(3): 282-298.

Van Vianen, A. E. M., U.-C. Klehe, J. Koen and N. Dries. 2012. Career Adapt-Abilities ScaleNetherlands form: Psychometric properties and relationships to ability, personality, and regulatory focus. Journal of Vocational Behavior 80(3): 716-724.

Wilkins, K., S. Santilli, L. Ferrari, L. Nota and S. Soresi. 2014. The relationship among positive emotional dispositions, career adaptability, and satisfaction in Italian high school students. Journal of Vocational Behavior 85(3): 329-338. 